\title{
CRISE DO ENSINO DE CIÊNCIAS HUMANAS NO BRASIL: EDUCAÇÃO, TRABALHO E DESENVOLVIMENTO
}

\author{
Rafael Ademir Oliveira de Andrade \\ Artur de Souza Moret
}

\section{Resumo}

Este trabalho é fruto de um conjunto de reflexões acerca do ensino de Ciências Humanas no Brasil. Partimos de uma perspectiva história da presença ou ausência desse ensino e respondemos a questões levantadas por setores do poder político da sociedade brasileira no ano de 2019 sobre a funcionalidade ou retorno do investimento público no ensino de Sociologia e Filosofia. Dessa forma, procuramos debater noções e planos sobre o desenvolvimento e sua relação com a educação e o trabalho, partindo de posturas interdisciplinares que possibilitem uma análise franca dos processos e possibilidades. Concluímos que a postura contrária ao ensino de Ciências Humanas se relaciona com diversos aspectos ideológicos: a crença evolucionista no desenvolvimento possível, a secundarização do plano social em detrimento ao plano econômico e a impossibilidade de análises que vão além das dicotomias ideológicas que permeiam o Estado e a sociedade brasileira.

Palavras-chave: Ensino. Ciências Humanas. Desenvolvimento. Trabalho.

\section{Introdução}

As primeiras questões que devemos refletir neste texto é sobre a natureza da crise da educação e do ensino de Ciências Humanas no Brasil: partimos do pressuposto, concordando com Darcy Ribeiro, que o distanciamento e precarização da educação e seus focos específicos é um projeto, não uma crise casual, neste mesmo diapasão Freire afirmou que a Elite não vai fazer Educação que seja capaz de levar os pobres a entenderem que são explorados.

O objetivo deste artigo é refletir sobre o ensino de Ciências Humanas nas configurações políticas e da organização do currículo no Brasil contemporâneo, assim como orientar possíveis impactos para a formação de novos profissionais da 
área, ampliação da pesquisa, inserção dos graduados nas diversas etapas da divisão social do trabalho, dentre outras questões.

Dessa forma, o que presenciamos de forma mais evidente agora é fruto de um processo intencional das classes hegemônicas, de silenciar as possibilidades intelectuais das massas, partindo da inviabilização do acesso a ferramentas de crítica as estruturas sociais que as Ciências Humanas, e seu ensino, possuem enquanto objetivo. Deste projeto de silenciamento, tão estudado nos cursos de graduação e pós-graduação em Educação, Sociologia, Filosofia, e afins, pretendemos neste trabalho, apontar alguns elementos que se relacionam com o que experimentam os pesquisadores e professores da área nos derradeiros quatro anos no Brasil.

Faremos, para ampliar discussões posteriores, reflexões em cinco tópicos interconectados, passando da crise do ensino das Ciências, da função do ensino, da nova "roupagem" da crise e, da relação entre ensino de Ciências humanas versus desenvolvimento. Essas temáticas surgem das ações de governos do Estado brasileiro e da declaração de autoridades nacionais sobre a "função" da Sociologia e Filosofia na construção de um estado desenvolvido. Os discursos fortalecidos pela fala pública desses agentes governamentais elevam e renovam as discussões acerca desta "utilidade" e, neste artigo a intenção é refletir sobre as aproximações e distanciamentos desses posicionamentos ideológicos.

\section{A crise/projeto do Ensino de Ciências Humanas não é algo "de 2019"}

Em 2008, após quatro décadas de silenciamento, o ensino de Sociologia e Filosofia se torna obrigatório no ensino médio (Lei no 11.684) e a partir de 2018 a resposta mais coesa sobre a continuidade desta obrigatória na nova composição curricular da educação básica no Brasil (ABECS, 2018) é "depende". Depende, pois a partir da nova BNCC (MEC, 2018) cabe aos estados e municípios fazer vale "estudos e práticas" que envolvam Sociologia e Filosofia - o que geralmente representa a exclusão ou precarização dos saberes e exclusão das disciplinas. A exclusão é dada de forma clara, não existência na matriz curricular, já a 
precarização ocorre de várias formas: atuação de professores não formados na área, diminuição da carga horária anual, realização da disciplina a partir de projetos alternativos, dentre outros.

A intenção é enxugar gastos da máquina estatal a partir desta precarização: no estado de Rondônia desde 2016 é aplicada a Mediação Tecnológica (inspirada em projeto do estado do Amazonas), que substitui professores em sala de aula por transmissões e, não raramente, vídeo-aulas, ampliando essas ações de precarização educacional sobre o ensino de Sociologia/Filosofia em contexto de escola rural, indígena e quilombola, não garantido os princípios de localidade, interculturalidade e criatividade docente dispostos na Constituição Federal e na LDB (1996) e uma das principais justificativas (apresentadas em Assembleia Legislativa em Junho de $2016^{48}$ ) é a diminuição dos gastos do estado com educação.

Bem como, aplicado na Sociologia/Filosofia, os elementos reflexivos inerentes a estas disciplinas são eliminados e apenas apresentados os conteúdos, ou seja, mediados com a tecnologia sem exercitar a reflexão dos alunos e alunas. Esses rápidos dados demonstram que há um interesse do Estado - desde sempre - em precarizar ou retirar o ensino de ciências que possibilitem a reflexão crítica das massas acerca dos fatos sociais.

Sintetizando este primeiro elemento, citamos que em "519 anos de Brasil" o ensino de Sociologia e Filosofia foi obrigatório não mais do que uma década, a estar sempre ao vento dos desejos ideológicos sua permanência ou não (FERNANDES, 1976 ) e que a crise não é um projeto, e adicionamos: não é um projeto recente.

\section{Apesar de não ser nova, tem "roupagem nova" em 2018/19}

Essa roupagem nova que apontamos tem duas faces, uma ideológica e outra econômica, que se inter-relacionam entre si, ou mesmo, a ação econômica é um reflexo da visão ideológica. Do ponto de visto ideológico há uma intenção do

\footnotetext{
${ }^{48}$ Para maiores informações, assistir a audiência em https://www.youtube.com/watch?v=rxutML5Y5Mw.
} 
governo atual em continuar - de forma mais agressiva e pública - as posturas ideológicas do governo anterior, Michel Temer.

Importante salientar isso: enquanto muitos agentes estavam em silêncio frente à diminuição dos investimentos em educação pública, regras mais impositivas aos programas de pós-graduação, redução/corte de bolsas de pesquisa, aprovação de medidas e alterações na LDB, discussão e aprovação da nova Base Nacional Curricular Comum, tentativa de aprovação do projeto Escola sem Partido, ataques violentos contra docentes e professores de Ciências Humanas já ocorriam desde 2016 - ataques que eventualmente se potencializaram a partir do posicionamento público de agentes governamentais atuais.

Essas ações já reverberam em concursos e currículos da educação básica e superior pelo Brasil e agora entramos na segunda fase do ataque ideológico: ao passo que o governo Temer agia como um político de gaveta aprovando seus projetos à revelia da população, o novo governo "alt-right" declara guerra ideológica aberta, direcionando a culpa do "atraso" brasileiro a agentes sociais que, de fato, nunca estiveram no poder: indígenas, negros, estudantes e professores "de tudo que não é útil", homossexuais e não normativo-centralizados de qualquer natureza.

Isso quer dizer que o aluno que ofende o colega por ser de religião afrobrasileira e a diretora que expulsa a criança indígena da escola urbana estão agora amparados pela política/postura/discurso público ideológica do governo. A intenção é afastar novamente esses agentes para a periferia da divisão do poder, pois apesar de tudo ocorreram avanços desses indivíduos dos espaços de poder ocupados.

É preciso refletir sobre as concepções de democracia e suas possibilidades, já que a democracia requer pluralidade, distribuição de poder e instituições que produzem pesos e contrapesos em suas diversas formas sociais, quais os possíveis impactos, em diferentes escalas, da soma dos interesses dos agentes políticos em retirar o ensino de Ciências Humanas visando economia, controle e imposição de uma nova ideologia hegemônica. 


\section{Outra postura, dependências imperialistas}

É reconhecido por diversos autores, sendo alguns citados em seguida em nosso texto, que há submissão do governo brasileiro aos interesses dos grandes centros capitalistas, especialmente os Estados Unidos da América e que esses grandes centros, de uma forma ou de outra, sempre exerceram suas influências sobre o Brasil: desde as reformas neoliberais na segunda metade do Século XX (ESCOBAR, 1995; SACHS, 2000) que impuseram gradualmente a agenda do Banco Mundial aos países da América Latina, passando pelo mini imperialismo brasileiro nas primeiras décadas do século XXI - representado pela postura do país na condução do plano IIRSA, por exemplo - até as viagens e acordos de benefício unilateral feitas pelo atual governo com os Estados Unidos da América.

A partir dessa análise, podemos afirmar que há um interesse (tanto do governo, quanto das bancadas de políticos, quanto dos agentes e Estados internacionais) de que o Brasil mantenha e reforce sua dependência econômica e intelectual dos grandes centros do capitalismo: diminuindo a potencialidade das bolsas e programas de pesquisa voltamos a depender exclusivamente das técnicas e resultados de pesquisas externas, assim como de seus produtos. Ensinando o povo brasileiro a reproduzir/obedecer/repetir práticas e saberes criamos a mão de obra necessária à continuidade da primarização do país e um país que estabelece suas relações de educação e trabalho neste contexto não precisa do ensino de Sociologia e Filosofia em larga escala.

Vendendo apenas produtos primários e consumindo produtos aprimorados pela tecnologia externa voltamos a velha relação colonial de dependência das "metrópoles". Ao mesmo tempo que responde aos interesses e pressões de seus "aliados" internacionais, o atual governo dá vazão ao ódio de classe e raça nutrido por brasileiros que se pensam elite ou "da burguesia" (JESSÉ DE SOUZA, 2017), matando dois coelhos "com uma cajadada só".

A elite econômica e cultural, como uma fiadora destas ações, tem o rentismo como principal ação econômica, porque não precisa de nenhuma autonomia de nação para se reproduzir, porque o dinheiro se move pelo mundo aportando-se apenas em ações e outros mecanismos financeiros, desligando-se de forma ainda 
mais crua do capital produtivo ao passo que o desemprego e a ausência do Estado criam um exército de reserva ainda mais efetivo (ANTUNES, 1993) onde as transformações das formas sociais do trabalho recriam a esfera para a acumulação contínua necessária as superações das crises ou travamentos do capital.

\section{Educação, trabalho e desenvolvimento - Estamos no sentido oposto}

A primeira grande questão, já relacionado ao debate anterior, é que "o tal desenvolvimento" passa pelas relações de produção e consumo. Isso quer dizer que mesmo pensando em microssistemas quanto em relações de capitalismo internacional é preciso refletir sobre o que se produz e como isso é consumido ou distribuído; Ladislau Dowbor (DOWBOR, 2017) destaca que a catástrofe econômica com milhões de miseráveis espalhados pelo mundo se deve ao capital improdutivo que não está ligado a produção.

Dessa forma pensando em capitalismo mundial a partir de Renato Ortiz e Carlos Taibo (ORTIZ, 1994; TAIBO, 2010) para que o Brasil ocupe o espaço de grande celeiro do mundo, de exportador de commodities de baixo valor agregado e consumidor de tecnologias externas, uma educação prática e um trabalho repetitivo é o suficiente para que essa postura neocolonial se consolide.

Há uma grande questão do discurso propalado pelas elites econômicas e que leva a crença da classe média de que o crescimento econômico (altas somas de exportação de commodities) pode levar ao bem-estar social e, sobretudo, a manutenção efetiva da classe média. Esse discurso é desfeito pelo olhar atento e crítico aos idosos chilenos pós-reforma da previdência (que inspira nossa proposta) e da atual situação da Argentina de Macri, descrito por Eric Hobbsbawn em A Era dos Extremos (1995) como o fim do welfare state norte americano.

Para romper com essa relação de dependência é preciso - a longo prazo que se incorpore ao Brasil uma visão de desenvolvimento inclusivo, incorporando e aprendendo com as minorias, perpassando pelo investimento em pesquisa, em industrialização (agregar valor), em educação para a inclusão e em cultura da inovação; para que estas ações sejam efetivadas é necessário compreender a 
sociedade e o papel das classes que são possíveis a partir da sociologia e da filosofia.

Entretanto, ao que parece estamos no caminho oposto: vendendo nossos setores produtivos, investindo em uma primarização social e ambientalmente agressiva, precarizando a pesquisa e inovação e retirando a possibilidade de formação crítica de nossos educandos. Muitos têm os EUA como modelo de desenvolvimento, mas atuando como atuamos no cenário internacional e nacional, estamos cada vez mais distantes deste ideal sugerido (FURTADO, 1973).

A tese que o professor Celso Furtado defende é justamente que, pensando na lógica da divisão mundial do trabalho, é de interesse dos países centrais que o Brasil continue nesta perspectiva de produção e distribuição de seus recursos ao passo que continua a defender a teoria evolutiva do caminho inexorável do sub ao desenvolvimento. Neste cenário de dependência econômica e tecnológica do capital e de governos estrangeiros, qual seria o papel das ciências e, mais especificamente, das Ciências Humanas na construção de uma massa trabalhadora "para as ciências" e para a solução efetiva dos problemas sociais?

Destacamos a fala do professor Saviani (2008) quando este, ao analisar a interrelação entre as divisões estruturais do ensino, aponta que a função social do ensino superior é refletir, e propor alternativas regionais, nacionais, endógenas, aos problemas da sociedade em que se insere.

Precisamos afirmar que esta função tem seu ponto de partida na reflexão sociológica/filosófica/antropológica das coisas em si: como esperar que uma sociedade proponha soluções para os problemas sociais que não conhecem? Do outro lado "da moeda" o capitalismo e suas estruturas nacionais/internacionais continuarão a financiar pesquisas para a ampliação da produção e outras formas de acumulação de capital que necessariamente não passam pelo desenvolvimento enquanto bem-estar social.

Apesar dessas discussões é preciso responder ao que é proposto: as Ciências Humanas dão retorno? A resposta desta primeira pergunta requer que outras questões sejam feitas, principalmente sobre a natureza e dimensão deste "retorno". É sobre esse tema que a conclusão deste trabalho se dirige. 


\section{Concluindo: Ciências Humanas não dão retorno?}

Este tópico é a conclusão do texto, apesar de não encerrar as discussões que se desenrolam na história recente, ou cotidiana, das violências estruturais e simbólicas sobre o ensino de Ciências Humanas e o acesso ao pensamento crítico que essas ciências dialogam.

É preciso explicar aos setores do governo brasileiro que apontam tal ineficiência das ciências humanas que mesmo nas esferas mais reprodutivas da divisão social do trabalho as ciências humanas - e seu ensino - possuem amplos espectros de atuação e funcionalidade. Para que a elite econômica ou intelectual possa manter o status quo e serem: empreendedores, criativos, tecnológicos, solucionadores, produtores de renda, capitalistas, membros da intelligentsia, etc., é preciso que os mesmos possam: saber o que criar, o que solucionar, como produzir renda, como lidar com pessoas, o que é o poder, dentre muitos outros saberes estudados nas Ciências Humanas e afins. É possível perceber que a praticidade da resposta neste primeiro momento busca responder única e exclusivamente aos anseios dos setores que provocaram a discussão.

Ao ensinar apenas a reproduzir lógicas e/ou modelos, o estudante médio não será capaz de propor soluções e criar algo novo. O sítio virtual da Harvard University pode informar ao novo governo da importância da interdisciplinaridade efetiva na criação de líderes sociais, como cursos sobre personalidades negras, meio ambiente, sustentabilidade, homo afetividade fazem parte da formação básica de todas as Schools da Universidade.

A $\mathrm{BBC}^{49}$ publica notícia sobre a formação em ciências humanas e mercado de trabalho, reforçando que as características mais procuradas pelas grandes empregadoras mundiais são competências sociais, humanas, críticas e interpessoais - objetivo das ciências humanas e sua presença nas graduações e na educação básica. A questão aqui não é sujeitar o ensino de humanidades ao crivo do

49 "Faculdades de humanas dão menos retorno que outras?", publicada em 26 de abril de 2019. Disponível em https://www.bbc.com/portuguese/geral-48071414, acessada em 23 de setembro de 2019. 
desenvolvimentismo norte-americano ou do mercado de trabalho, mas de definir uma lógica simples: se os agentes que atacam tal ensino afirmam buscar a criação de empregos e o desenvolvimento do país, estão na contramão do país que coordena o eixo capitalista nas ações para o crescimento econômico.

Sabemos também duas coisas: não há preocupação do atual governo com o desenvolvimento do país (apesar do discurso e por isto me aproprio dele) e estamos falando dos mesmos políticos de carreira no poder que, diferente dos brasileiros em geral, não precisam da criatividade e da crítica para se reinventar e continuar trabalhando diariamente, muitas das vezes pela própria sobrevivência.

A intrínseca relação entre educação e trabalho que se instaura após as revoluções industriais e a expansão do capitalismo levou as elites econômicas nacionais e internacionais a busca pelo estreitamento da relação entre ensino superior, pesquisa e produção, visando a lucratividade dessas ações e quando o governo atual fala de "ciências que dão retorno" este expressa a perspectiva de que ensino deve ser igual a lucro. A questão é, lucro para quem?

Apesar de vivermos uma crise no plano social, visto que o mesmo não é encarado como um impedimento para o crescimento - o "mundo" se torna mais pobre mesmo que uma minoria se torne cada vez mais rica (DOWBOR, 2017). A questão é que o crescimento não tem relação alguma com o bem-estar social, normalmente é medido pelo aumento do PIB e não pelo IDH, para utilizar elementos simples de análise.

Nesta conexão de dados, concluímos que o não investimento em ciências humanas pela justificativa que "não dão retorno" nos fala exatamente sobre as intenções de orientar as forças governamentais para a ampliação do mercado em detrimento do investimento no plano social. É preciso investir naquilo que dá retorno, entretanto, sem possibilitar às massas a reflexão sobre suas condições e formas de ampliar suas potências criativas na solução local ou ampla de suas necessidades em longo prazo, para quem será este retorno? 


\section{Referências}

ABECS. Vai ter sociologia no ensino médio? Associação Brasileira de Ensino de Ciências Sociais, Blog de notícias, 2018. Acessado em 01/05/2019, link para acesso em https://abecs.com.br/vai-ter-sociologia-no-ensino-medio/

ANTUNES, Ricardo. Adeus ao Trabalho: ensaio sobre as metamorfoses e a centralidade do Mundo do Trabalho. São Paulo: Editora Paulinas, 1993.

BRASIL. Lei n. 9.394, de 20 de dezembro de 1996. Lei de Diretrizes e Bases da Educação Nacional. Brasília, DF: 20 de dezembro de 1996.

DOWBOR, Ladislau. A era do Capital improdutivo. São Paulo: Ed. Outras Palavras e Autonomia Literária, 2017.

ESCOBAR, Arturo. Encountering Development: The making and unmaking of the third world. Chichester: Princeton University Press, 1995.

FERNANDES, Florestan. A Sociologia no Brasil: Contribuição para o Estudo de sua Formação e Desenvolvimento. Petrópolis: Vozes, 1976.

FURTADO, Celso. O Mito do Desenvolvimento Econômico. Rio de Janeiro: Paz e Terra, 1973.

HOBBSBAWN, Eric. Era dos Extremos: O breve século XX (1914-1991). Tradução Marcos Santarrita. 2 ${ }^{\mathrm{a}}$ Ed. São Paulo: Companhia das Letras, 1995.

MEC. Base Normal Curricular Comum. Brasília: Ministério da Educação, 2018.

ORTIZ, Renato. Mundialização e cultura. 3ª ed. São Paulo: Brasiliense, 1994.

SACHS, Wolfgang. Dicionário do desenvolvimento: Guia para o Conhecimento como Poder. Petrópolis: Vozes, 2000.

SAVIANI, Dermeval. História das Ideias Pedagógicas no Brasil. $2^{\underline{a}}$ Edição. Campinas: Autores Associados, 2008.

SOUZA, Jessé de. A elite do atraso: da escravidão à Lava Jato. Rio de Janeiro: Leya, 2017.

TAIBO, Carlos. Decrescimento, Crise, Capitalismo. Rio de Janeiro: Editora Estaleiro, 2010. 